\title{
Education for innovation: engineering, management and design multidisciplinary teams of students tackling complex societal problems through Design Thinking
}

Charosky, Guido ${ }^{a}$; Hassi, Lotta ${ }^{b}$; Leveratto, Lucianac; Papageorgiou, Kyriaki ${ }^{\text {; }}$; Ramos, Juan'; Bragos, Ramon ${ }^{\mathrm{e}}$

${ }^{a}$ Department of Management, Universitat Politécnica de Catalunya, Spain, ${ }^{b}$ Department of Operations, Innovation and Data Sciences, ESADE, Spain ${ }^{\mathrm{c}}$ Master Department, Istituto Europeo di Design, Spain ${ }^{\mathrm{d} I n s t i t u t e}$ for Innovation and Knowledge Management, ESADE, Spain ${ }^{\mathrm{e}}$ Department of Electronic Engineering, Universitat Politécnica de Catalunya, Spain

\begin{abstract}
Innovation education involves a different approach both for professors and students. It requires understanding people, technology and business to develop truly innovative solutions that can succeed in the market.

The aim of this paper is to analyze the benefits, learning outcomes and selflearning perception about innovation from students participating in an innovative learning experience co-developed by an Electrical Engineering School, a Business School and a Design Institute. Challenge Based Innovation (CBI) is a program created by CERN to host educational projects where multidisciplinary teams of students tackle innovation challenges. The objective is to design solutions to social problems through Design Thinking. It was observed that engineering students, after this learning experience increase their understanding of user's needs and the relevance of focusing on them when approaching innovation challenges. Also, they improve their ability to ideate break-through solutions thanks to a better understanding of the relationship between people, business and technology due to their indepth interaction with management and design students. Furthermore, their self-confidence is significantly increased along with their entrepreneurial skills. The level of engineering student's understating of innovation as a whole is higher with this approach compared to standard design-build projects performed at the Engineering Schools.
\end{abstract}

Keywords: Design Thinking, Innovation, Challenge Based Education, Multidisciplinary projects 


\section{Introduction}

The understanding of the design process is important both to manage the design activity and to aid the improvement of products and the overall efficiency of engineering based companies (Howard, Culley, Dekoninck, 2008). It is also fundamental to tackle innovation challenges and to minimize uncertainty during the innovation process. It is also important for engineering students to understand the overall process and going beyond the purely engineering skills or activities.

Originally developed at the Massachusetts Institute of Technology, the CDIO framework (Crawley et al. 2014), defines 4 phases for the product development cycle: Conceive, Design, Implement and Operate.

The Conceive stage includes defining customer needs, understanding technology, company strategy, and regulations and developing conceptual, technical, and business plans. Nevertheless, the emphasis of the Syllabus section 4 of the CDIO Syllabus 2.0 is mainly in the "Design". Also, most engineering schools curricula focuses on this phase, generally starting projects from requirements or even directly from specifications (Hassi et al., 2016). In the professional world, also is often assumed that engineers need another agent to state the requirements (design, marketing, management...).

Although engineering students feel comfortable with this approach, it limits the capabilities of graduated engineers on influencing on strategy and concept definition for new products and services.

In the past years, new approaches to innovation like Co-Creation and Design Thinking (Brown, 2008) have arisen as methodologies to dealing with uncertainty involved in the "Conceive" phase of any innovation project. Some references can be found about this approach (Yang et al., 2014) (Ping et al., 2011).

According to Dym et al. 2005, the currently most-favored pedagogical model for teaching design is project-based learning (PBL), using Design Thinking.

The aim of this work is to describe and discuss the benefits and learning outcomes detected along four iterations of a multidisciplinary challenge based learning experience carried out by three institutions from Barcelona: an Engineering School, a Design School and a Business School. This study is focused on the Engineering students. 
Education for innovation: engineering, management and design multidisciplinary teams of students tackling complex societal problems through Design Thinking

\section{Design Thinking}

Searching for new ideas and innovative solutions to complex problems (either business, social, educational or others) it is inheritably uncertain and has less certain outcomes than the improvement of existing solutions. Innovation is uncertain by definition.

At the outset of an exploration project, there is neither a clear predefined target, nor a known route to achieve it, certainly no requirements nor specifications. In opposition, classical engineering student projects or even modern engineering capstone projects often start from requirements or even directly from specifications provided by an external or internal stakeholder (Hoffman, 2014).

Design Thinking is an approach to innovation that helps to deal with uncertainty, understanding user needs, exploring solutions and ideas, and validating them through an iterative rough and quick prototyping process. It is a human-centered methodology that uses the tools and methods from the design disciplines and it is recognized for its clear bias towards abductive and integrative thinking, exploration and visualization. According to Rattcliffe (2009), the Design Thinking process can be separated in two clear "spaces": the problem space and the solution space. From the cognitive perspective, it is a divergent and convergent process combined, where a set of alternatives are created and only then, choices are made based between the different options (Brown, 2009). It is a process composed of six iterative phases involving back-and-forth movements between the phases in a non-linear way (Figure 1). The phases are Understand, Observe, Point of view, Ideate, Prototype and Test.

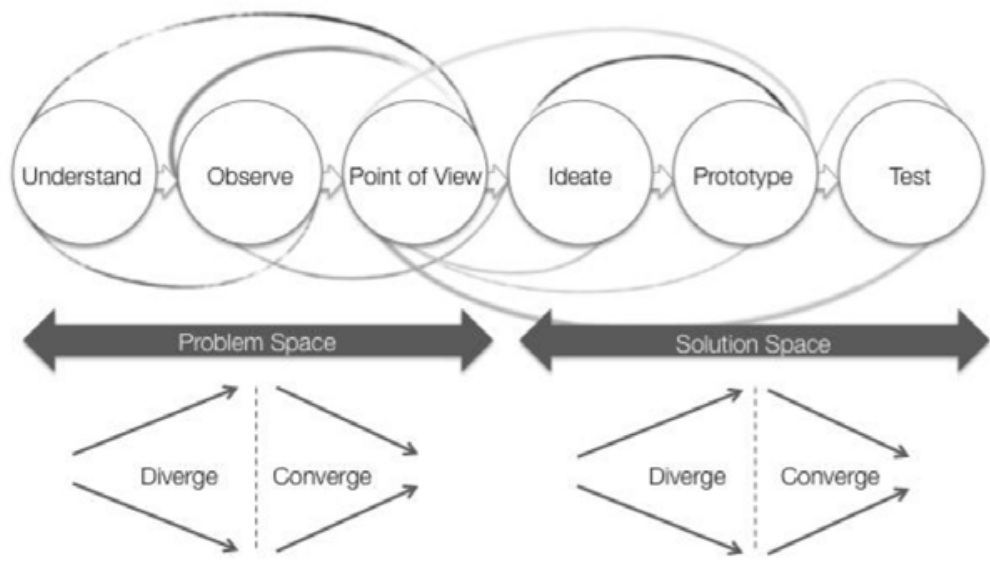

Figure 1. Adapted from Rattcliffe (2009) 


\section{Mixing engineering, design and management students at CERN to solve social challenges}

Challenge Based Innovation (CBI) is a program created by CERN, the European Organization for Nuclear Research, to host educational projects in which students from different disciplines, universities and nationalities are put together in multidisciplinary teams to tackle innovation challenges. The objective for the students is to design solutions to social problems through the innovation methodology called Design Thinking.

During one semester the students spend 3-4 weeks at IdeaSquare (http://ideasquare.web.cern.ch/), a creative environment created at CERN Meryin site in Switzerland, where they can consult and interact with scientists and knowledge transfer experts about possible applications and uses of CERN technologies in the student's proposed solutions.

Management, Design and Engineering schools usually perform project or case based courses about product or service development, but the fulfillment of the aforementioned design phases gains a lot of added value if the three agents of the process participate simultaneously on it because they cover the three key aspects: economic viability, usability/desirability and technical feasibility. The three institutions started performing shared activities four years ago, being the most relevant one the one that is performed in collaboration with IdeaSquare at CERN.

Together with IdeasSquare staff and mentors and faculty from the three different universities, teams draw inspiration from relevant novel technologies and create tangible prototypes. In three out of four editions, the teams have also included students from universities of other countries.

The basic structure of CBI course is divided into three parts: Discover, Design and Deliver (Design Council, 2005). In the Discovery phase, the student teams deep dive into their societal challenges, seeking to understand the "big picture" and in depth user needs. The phase ends with a clear statement and specific need or problem to address within its challenge. In the Design phase, the teams create quick and rough prototypes of the solutions for the needs they have discovered and then they test with users to get feedback. They choose one of the concepts and in the Delivery phase, this concept is developed including a functional, proof-of- concept prototype. At the end, the results are presented in a gala at CERN.

Some examples of the challenges tackled in CBI are: allowing people to restore or enhance their ability to move, providing a way for safe and fair distribution of electric power in refugees' camps or improving the water usage in developing countries. 
A risk of this kind of multidisciplinary activities is the possibility that the students of a given discipline remain in their silo and only develop skills related with their previous knowledge. This is avoided by a course time plan, which drives all the students through all the design phases by doing collaborative activities, often taking them out of their comfort zone. There are also short lectures on key disciplines aspects oriented to all the students. Only in the last step (final proof-of-concept prototype) the engineering students devote more time to the technical development, the business students to the business plan and the design students to the graphical and communication aspects of the final presentation, reports and video, but even in this last phase the cooperation is intense thanks to the fact of being performed in a 10 days intensive period.

\section{Challenge-based learning}

According to Malmqvist et al. (2015) a challenge-based learning experience "is a learning experience where the learning takes places through the identification, analysis and design of a solution to a sociotechnical problem. It is typically multidisciplinary, takes place in an international context and aims to find a solution, which is environmentally, socially and economically sustainable.”

It could be said that challenge-based learning is an evolution of problem-based learning, with a more holistic approach. In problem-based learning, students are required to tackle a a design, research or technical problem and their learning occurs in the process of working on the solution, normally in teams with the same or similar skills (i.e. engineering students).

Challenge-based learning experiences are more complex but more enriching, as they expose the students to work in multidisciplinary teams, and to address more complex societal challenges. These challenges combine not only the societal goals and the technical solutions, but also the business development or business model required to tackle them.

In this multidisciplinarity, students get to understand how other disciplines' professionals think, talk, tackle problems, face uncertainty, make decisions,... This type of interactions are extremely beneficial to prepare engineers to manage real life innovation challenges, where multidisciplinarity is mandatory and understanding "the big picture" and understaning the needs and objectives of all stakeholders is fundamental.

The evolution from problem-based learning to challenge based learning in engineering education is illustrated in Table 1, where key aspects of each approach are compared. Main differences are the different disciplines involved in challenge-based (engineering and business) versus only engineering in problem-based. Also, the main activities that go from designing the solution in problem-based to formulating the problem and then designing the solution in challenge-based education. 
Charosky, G.; Hassi, L.; Leveratto, L.; Papageorgiou, K..; Ramos, J.; Bragos, $R$.

Table 1. The evolution from problem-based learning to challenge based learning is illustrated in table 1 highlighting key aspects of each approach

\begin{tabular}{|c|c|c|}
\hline & Problem-based & Challenge-based \\
\hline Disciplines involved & Engineering & Engineering \& business \\
\hline Context & Product context & Societal context \\
\hline $\begin{array}{l}\text { Main activities developed } \\
\text { Working model }\end{array}$ & $\begin{array}{c}\text { Designing the solution } \\
\text { Team based }\end{array}$ & $\begin{array}{l}\text { Problem formulating \& designing } \\
\text { the solution }\end{array}$ \\
\hline Main focus & Customer needs & $\begin{array}{c}\text { Team based and individual } \\
\text { Customer needs and societal value } \\
\text { creation }\end{array}$ \\
\hline
\end{tabular}

\section{Conclusions and learning outcomes}

According to the feedback surveys and personal reflections performed by the students in the four course editions, the most valuable learning outcomes, above the singularity of CERNrelated issues and the international experience are the aspects derived from the multidisciplinarity: knowing the way the others think, their tools and methods, being able of giving the right value to the other's work and developing a common language.

As one student mentions about his main take away from the course: "How to work with people from other disciplines, understanding their points of view, in order to come up with the best solution to a problem not only from a technological approach.” The understanding of innovation beyond technology and engineering is one of the great achievements of this learning experience when talking about engineering students.

In the specific case of engineering students, in addition to the multidisciplinary values, there is a clear improvement in self-confidence and also a clear increase of user-awareness. Also, they gain a broader understanding of the value delivered by a product or service, on top of the technical functionality.

Regarding innovation, when asked what they understood by innovation before taking this course, reponses are mainly related to creating something new or improving something existing. When asked the same question after the course, there are some similar responses but is significant the appearance of many asnwers regaridng impact on the society , 
Education for innovation: engineering, management and design multidisciplinary teams of students tackling complex societal problems through Design Thinking

solutions to real needs, finding problems and being able to changing your point of view as you gain more knowledge through research and prototyping.

From the methodological point of view, the students appreciate the intensive periods, although the regular academic year schedule does not have the needed flexibility to perform that kind of activities and the students have to do an extra effort to follow this course.

According to the surveys, engineering students agree that their knowledge on innovation increased significantly after taking the CBI course, as well as their business sense.

\section{References}

Brown, T. (2008). Design Thinking. Harvard Business Review, (June 2008).

Crawley, E. F., Malmqvist, J., Östlund, S., Brodeur, D. R., \& Edström, K. (2014). Rethinking engineering education: The CDIO approach, second edition. https://doi.org/10.1007/978-3-319-05561-9

Dym, C. L., Agogino, A. M., Ozgur, E., Frey, D. D., \& Leifer, L. J. (2005). Engineering Design Thinking, Teaching, and Learning. Journal of Engineering Education, (January).

Hassi, L., Ramos-Castro, J., Leveratto, L., Kurikka, J. J., Charosky, G., Utriainen, T. M., Bragos, R., Nordberg, M. (2016). Mixing Design, Management and Engineering Students in Challenge-Based Projects. Proceedings of the 12th International CDIO Conference, Turku University of Applied Sciences.

Hoffman, H.F., (2014), The engineering capstone course. Fundamentals for students and instructors. New York, USA, Springer.

Howard, T. J., Culley, S. J., \& Dekoninck, E. (2008). Describing the creative design process by the integration of engineering design and cognitive psychology literature. Design Studies, 29(2), 160-180. https://doi.org/10.1016/j.destud.2008.01.001

Malmqvist, J., Rådberg, K., \& Lundqvist, U. (2015). Comparative Analysis of ChallengeBased Learning Experiences. Proceedings of the 11th International CDIO Conference, Chengdu University of Information Technology, Chengdu, Sichuan, P.R. China, June 811, 2015

Ping, C. S., Chow, P., Teoh, C. (2011) The Use of Design Thinking in C-D-I-O Projects. Proceedings of the 7th International CDIO Conference, Technical University of Denmark, Copenhagen, June 20 -23, 2011.

Ratcliffe, J. (2009). Steps in a design thinking process. https://dschool.stanford.edu/groups/k12/wiki/17cff/ (retrieved 04-04-2013).

Yang, K.Y.E. and Cheah, S.M. (2014) Chemical product design as foundation for education as sustainable development. Proceedings of the 10th International CDIO Conference, Universitat Politècnica de Catalunya, Barcelona, Spain, June 16-19, 2014 